\title{
Composition of Pulmonary Lavage Fluid in Control and Reserpine-treated Rats following Chronic Isoproterenol and Pilocarpine Administration
}

\author{
THOMAS P. MAWHINNEY, ${ }^{(22)}$ J. RICARDO MARTINEZ, MILTON S. FEATHER, AND GIULIO J. \\ BARBERO
}

Departments of Child Health and Biochemistry, University of Missouri School of Medicine, Columbia, Missouri, USA

\begin{abstract}
Summary
Lung lavage samples were obtained in control and reserpinetreated rats after they were given 12 daily IP injections $(10 \mathrm{mg})$ of either isoproterenol or pilocarpine. Similar samples were obtained from other control and reserpine-treated animals that received no secretagogue for 12 days. In the latter group, the total protein, lipid, and carbohydrate contents of the lavage samples were similar in control and reserpine-treated rats. Chronic isoproterenol administration caused a 2.5-fold increase in the lipid content, but no change in the protein or carbohydrate contents, of pulmonary lavage samples of control rats. In reserpine-treated rats, however, the same isoproterenol treatment caused a 2.6-, 6.0-, and 1.9-fold increase, respectively, in the protein, lipid, and carbohydrate contents of lavage samples. Chronic treatment with pilocarpine resulted in a 2.6-, 3.3-, and 1.9-fold increase in the protein, lipid, and carbohydrate contents of control samples and a 12.5-, 5.6-, and 9.3-fold increase in the same components of lavage samples from reserpine-treated rats. The increase in total lipid content observed in control and reserpine-treated rats after chronic isoproterenol administration and in control rats after chronic pilocarpine treatment was not accompanied by changes in the percent distribution of the various lipid fractions. In reserpine-treated rats receiving pilocarpine for 12 days, however, the increased lipid content was due primarily to a significant increase in the phospholipid content, specifically phosphatidylcholine. Although the increased carbohydrate content observed in lavage samples of reserpine-treated rats after chronic isoproterenol administration or in control rats after pilocarpine administration was not associated with changes in the percentage of distribution of the various sugar fractions, the increase induced by chronic pilocarpine treatment in reserpinetreated animals was accompanied by increases in the fucose, galactose, and sialic acid contents. It is concluded that: (1) previous reserpine administration enhances the secretion of glycoprotein in the rat airways, particularly in response to longterm pilocarpine treatment; (2) it also results in an increased content of lipids, particularly the phospholipid phosphatidylcholine; (3) this effect is no longer evident, however, 13 days after cessation of reserpine injections. These alterations in respiratory tract secretions of reserpine-treated rats resemble those observed in cystic fibrosis and, in conjunction with other exocrine gland changes, suggest that this proposed model may be used to elucidate pathogenetic mechanisms in cystic fibrosis.
\end{abstract}

\section{Speculation}

The animal model for cystic fibrosis developed by chronic reserpine administration to rats has been shown to have significant elevations in the glycoprotein and lipid content of pulmonary lavage samples which were further enhanced when reserpine treatment was followed by acute pilocarpine stimulation. The present study has shown that chronic pilocarpine administration after reserpine pretreatment dramatically increased the glycoprotein content in pulmonary lavage samples and that the effect produced by chronic isoproterenol administration on lavage glycoprotein composition, although increased, was less marked. Both pilocarpine and isoproterenol caused increases in lavage lipids, but only pilocarpine significantly augmented the phospholipid fraction. We speculate that the hypersecretion of pulmonary glycoproteins and the increase in airway lipids exhibited by reserpine-treated rats when challenged chronically with specific neuropharmacologic agents makes this model an excellent tool for further studies directed towards the elucidation of the pulmonary mucus hypersecretion seen in cystic fibrosis.

Previous evidence has demonstrated that, compared to control animals, rats treated in a chronic fashion with reserpine show an increase in the protein, carbohydrate, and lipid content of pulmonary lavage fluid and also an enhanced secretion of these components following acute stimulation with pilocarpine (10). The hypersecretion of glycoprotein in the reserpine-treated animal is similar to that seen in certain chronic pulmonary diseases, particularly cystic fibrosis (CF) $(2,4,5,13)$ and suggests that the drug treatment alters the mucus-secreting elements in the respiratory tract. These observations, together with others in various exocrine glands and secretions $(8,9,11,17)$, lend support to the view that the reserpine-treated rat is a useful model for the study of the exocrine gland disturbance in CF.

Pulmonary glycoproteins are presumably secreted from various cell sources, primarily from the submucosal glands and the goblet cells $(4,13,15)$. The former secrete in response to cholinergic stimulation $(4,5,15,21)$, but the response of goblet cells to autonomic agents is still somewhat controversial $(4,13,21)$. Sturgess and Reid (16), however, have presented evidence showing that goblet cell numbers increase in the rat airways after chronic administration of isoproterenol and pilocarpine. This regimen also increased the size of submucosal gland acini. Inasmuch as an increase in goblet cells and submucosal gland hypertrophy are thought to be the basis for mucus hypersecretion $(5,13)$, this study was carried out to determine if previous treatment with reserpine enhanced the effects of chronic isoproterenol or pilocarpine administration as described by Sturgess and Reid. To this effect, the organic composition of pulmonary lavage fluid has been compared in control and reserpine-treated rats that subsequently received daily injections of either isoproterenol or pilocarpine for 12 days.

\section{MATERIALS AND METHODS}

Sixty-two adult male Sprague-Dawley rats (150 to $200 \mathrm{~g}$ ) fed $a d$ libitum and weighed every day were utilized in this experiment. 
Thirty animals were each administered a single daily IP injection of reserpine $(0.5 \mathrm{mg} / \mathrm{kg}$ body weight) for 7 days. Thirty-two animals not given reserpine were designated as controls. On the eighth day, three groups were formed, each consisting of a designated number of control and reserpine-treated animals. Group 1 rats received no further treatment from the eighth to the nineteenth days. For the same period, group 2 animals were each given a daily $10 \mathrm{mg}$ IP injection of pilocarpine nitrate, and group 3 rats were administered daily $10 \mathrm{mg}$ IP injections of isoproterenol sulfate. On the twentieth day, without further drug administration, all rats were anesthetized with $8.0 \mathrm{mg} / 100 \mathrm{~g}$ body weight of sodium pentobarbital, the tracheas were exposed and cannulated, and the lungs were lavaged with two $12-\mathrm{ml}$ volumes of sterile saline.

This procedure allows the collection of overall pulmonary secretions but does not establish the source of the different components analyzed. It has, therefore, some limitations, particularly in terms of variable recoveries. The method provides, nevertheless, baseline information about the overall composition of pulmonary airway secretions and of the changes that may occur in these secretions after stimulation with various types of drugs. In these experiments, the primary interest was the protein, carbohydrate, and lipid contents of the lavage samples, rather than cell recovery. Lavage volume was chosen based on consistent recoveries of airway proteins and lipids $(>87 \%)$ with minimal contamination of transudated plasma proteins. Samples containing red blood cells or hemolytic products were excluded from this study.

Pooled saline lavages of each rat were centrifuged at $950 \times g$ for $30 \mathrm{~min}$ at $4^{\circ} \mathrm{C}$ and exhaustively dialyzed against distilled water containing $0.001 \%$ ethylenediaminetetraacetate, and the resultant dialysates were lyophilized and delipidated with l-butanol:acetone $(1: 1, v / v)$ and ether:chloroform:methanol (1:2:1, v/v). Pooled organic solvents for each lavage sample were dried under nitrogen, and the lipids were weighed. Separation of neutral lipid, glycolipid, and phospholipid fractions was accomplished by silica gel chromatography (14). Neutral (18) and phospholipid (12) subclasses were separated by thin-layer chromatography. Esterified and free cholesterol were determined by the direct Liebermann-
Burchard reaction (3), and phospholipid phosphorus was assayed by the procedure of Lowry and Tinsley (7).

Delipidated lavage residues were rehydrated, and aliquots were assayed for total protein (6) and individual neutral sugars (10). Hexosamines were quantified by the procedure of Boas (1), and sialic acid was determined by the thiobarbituric acid procedure (20).

\section{RESULTS}

As noted in Table 1, the protein, lipid, and carbohydrate contents of lavage samples from animals administered reserpine were not significantly different from parallel untreated control values when samples were collected 2 wk after termination of reserpine treatment (group 1). Similarly, there was no significant difference in body weights between reserpine-treated $(247 \pm 23 \mathrm{~g}$ \pm S.D.) and untreated control $(268 \pm 34 \mathrm{~g} \pm$ S.D. $)$ rats in this experimental group. Lavage samples from group 2 control animals which received daily injections of pilocarpine (12 days) demonstrated a 2.6-, 3.3-, and 1.9-fold increase in their protein, lipid, and carbohydrate content, respectively, when compared to group I control values. Although increased, there was no concommitant change in the percent distribution of individual neutral lipid, phospholipid, or carbohydrates (Tables 2 to 4). Group 2 animals that were pretreated with reserpine prior to pilocarpine administration for 12 days had a highly significant 12.5-, 5.6-, and 9.3fold increase in lavage total protein, lipid, and carbohydrate content, respectively, when compared to group 1 values. This increase was accompanied by a significant elevation in lavage content of phosphatidylcholine (Table 3 ) and of fucose, galactose, and sialic acid (Table 4). Group 3 control rats which were chronically treated with isoproterenol showed a significant increase in lavage lipid only, with no change in the percentage of distribution of any individual lipid assayed. Animals pretreated with reserpine prior to chronic isoproterenol administration demonstrated a significant 2.6-, 6.0-, and 1.0-fold increase in lavage protein, lipid, and carbohydrate content, respectively. The percentage of distribution of individual lipids and carbohydrates remained unchanged.

Table 1. Protein, Lipid, and Carbohydrate composition of rat lung lavage ${ }^{1}$

\begin{tabular}{|c|c|c|c|c|c|c|c|}
\hline Group & Drug administration & Type of animal & $N^{2}$ & & \multicolumn{2}{|c|}{ Total } & $\mu \mathrm{g} / \mathrm{g}$ body wt. \\
\hline \multirow[t]{6}{*}{1} & None & Control & 10 & Protein & $1.02 \mathrm{mg}$ & $(0.11)$ & $2.72(0.24)$ \\
\hline & . & & & Lipid & $0.61 \mathrm{mg}$ & $(0.08)$ & $1.63(0.18)$ \\
\hline & & & & Carbohydrate & $51.1 \mu \mathrm{g}$ & $(3.0)$ & $0.14(0.01)$ \\
\hline & & Reserpine & 8 & Protein & $0.93 \mathrm{mg}$ & $(0.20)$ & $2.72(0.29)$ \\
\hline & & & & Lipid & $0.58 \mathrm{mg}$ & $(0.17)$ & $1.70(0.22)$ \\
\hline & & & & Carbohydrate & $54.0 \mu \mathrm{g}$ & $(2.4)$ & $0.16(0.01)$ \\
\hline \multirow[t]{6}{*}{2} & Pilocarpine & Control & 15 & Protein & $2.75 \mathrm{mg}$ & $(0.38)^{3}$ & $7.16(1.13)^{3}$ \\
\hline & & & & Lipid & $2.08 \mathrm{mg}$ & $(0.41)^{3}$ & $5.42(1.04)^{3}$ \\
\hline & & & & Carbohydrate & $98.5 \mu \mathrm{g}$ & $(6.1)^{3}$ & $0.26(0.04)^{3}$ \\
\hline & & Reserpine & 13 & Protein & $12.14 \mathrm{mg}$ & $(3.37)^{4}$ & $34.10(5.40)^{4}$ \\
\hline & & & & Lipid & $3.41 \mathrm{mg}$ & $(0.77)^{4}$ & $9.58(1.92)^{4}$ \\
\hline & & & & Carbohydrate & $529.0 \mathrm{mg}$ & $(42.4)^{4}$ & $1.49(0.28)^{4}$ \\
\hline \multirow[t]{6}{*}{3} & Isoproterenol & Control & 10 & Protein & $1.12 \mathrm{mg}$ & $(0.22)$ & $2.89(0.30)$ \\
\hline & & & & Lipid & $1.57 \mathrm{mg}$ & $(0.62)^{3}$ & $4.05(1.09)^{3}$ \\
\hline & & & & Carbohydrate & $51.4 \mu \mathrm{g}$ & $(2.7)$ & $0.13(0.03)$ \\
\hline & & Reserpine & 9 & Protein & $2.51 \mathrm{mg}$ & $(0.42)^{3}$ & $6.95(2.17)^{3}$ \\
\hline & & & & Lipid & $3.52 \mathrm{mg}$ & $(0.62)^{4}$ & $9.75(2.14)^{4}$ \\
\hline & & & & Carbohydrate & $98.0 \mu \mathrm{g}$ & $(8.4)^{3}$ & $0.27(0.10)^{3}$ \\
\hline
\end{tabular}

${ }^{1}$ Data expressed as mean \pm S.D.

${ }^{2} \mathrm{~N}$, number of animals.

${ }^{3}$ Significance of $P<0.005$ when compared to group I control or reserpine values.

${ }^{4}$ Significance of $P<0.0001$ when compared to parallel group control or to group 1 control or reserpine values. 
Table 2. Lipid composition of tracheobronchial lavage fluid ${ }^{1}$

\begin{tabular}{|c|c|c|c|c|c|c|c|}
\hline Group & $\begin{array}{c}\text { Drug } \\
\text { administration }\end{array}$ & $\begin{array}{l}\text { Type of } \\
\text { animal }\end{array}$ & $N^{2}$ & $\begin{array}{c}\text { Neutral } \\
\text { lipid }\end{array}$ & $\begin{array}{l}\text { Esterified } \\
\text { cholesterol }\end{array}$ & $\begin{array}{c}\text { Free } \\
\text { cholesterol }\end{array}$ & Phospholipid \\
\hline \multirow[t]{2}{*}{1} & None & Control & 10 & $27.71(2.60)$ & $16.02(3.50)$ & $6.92(1.93)$ & $44.50(4.61)$ \\
\hline & & Reserpine & 8 & $24.43(4.50)$ & $17.88(2.27)$ & $5.48(3.70)$ & $48.13(3.11)$ \\
\hline \multirow[t]{2}{*}{2} & Pilocarpine & Control & 15 & $29.41(3.00)$ & $15.18(3.39)$ & $5.94(1.67)$ & $41.77(6.01)$ \\
\hline & & Reserpine & 13 & $18.72(3.06)$ & $11.99(1.07)$ & $4.08(2.32)$ & $56.87(4.73)^{3}$ \\
\hline \multirow[t]{2}{*}{3} & Isoproterenol & Control & 10 & $22.85(2.47)$ & $19.00(3.81)$ & $7.70(2.08)$ & $47.37(4.11)$ \\
\hline & & Reserpine & 9 & $20.74(2.00)$ & $13.39(4.71)$ & $6.62(1.73)$ & $45.57(4.81)$ \\
\hline
\end{tabular}

${ }^{1}$ Data expressed as percentage of total lipid \pm S.D.

${ }^{2} N$, number of animals.

${ }^{3}$ Significance of $P<0.005$ when compared to parallel control or group 1 control and reserpine-treated animal values.

Table 3. Phospholipid analysis of tracheobronchial lavage fluid ${ }^{1}$

\begin{tabular}{|c|c|c|c|c|c|c|c|}
\hline Group & $\begin{array}{c}\text { Drug } \\
\text { administration }\end{array}$ & $\begin{array}{l}\text { Type of } \\
\text { animal }\end{array}$ & $N^{2}$ & $\mathrm{PE}^{3}$ & PS & PI & PC \\
\hline \multirow[t]{2}{*}{1} & None & Control & 10 & $7.2(1.3)$ & $5.1(0.81)$ & $0.9(0.09)$ & $61.9(4.4)$ \\
\hline & & Reserpine & 8 & $8.1(2.0)$ & $4.6(1.0)$ & $0.5(0.09)$ & $64.5(5.2)$ \\
\hline \multirow[t]{2}{*}{2} & Pilocarpine & Control & 15 & $6.6(1.7)$ & $2.7(1.1)$ & Too low & $64.8(3.4)$ \\
\hline & & Reserpine & 13 & $7.7(0.8)$ & $3.3(1.5)$ & $0.6(0.1)$ & $85.9(5.5)^{4}$ \\
\hline \multirow[t]{2}{*}{3} & Isoproterenol & Control & 10 & $8.2(1.6)$ & $4.8(1.3)$ & $0.7(0.24)$ & 70.8 (3.6) \\
\hline & & Reserpine & 9 & $7.9(2.1)$ & $5.4(1.5)$ & $1.2(0.41)$ & $68.4(2.8)$ \\
\hline
\end{tabular}

${ }^{1}$ Data expressed as percentage of total phospholipid \pm S.D. Recovery of phospholipids assayed, following silica gel column chromatography and thin-layer chromatography and based on phospholipid standards, was in excess of $92 \%$. Minor phospholipid fractions present in rat lung lavages were not assayed.

${ }^{2} \mathrm{~N}$, number of animals.

${ }^{3}$ PE, phosphatidylethanolamine; PS, phosphatidylserine; PI, phosphatidylinositol; PC, phosphatidylcholine.

${ }^{4}$ Significance of $P<0.005$ when compared to parallel control, group 1, or group 3 values.

Table 4. Carbohydrate composition of rat lung lavage $e^{1}$

\begin{tabular}{clrccccc}
\hline Group & & $N^{2}$ & Fucose & Mannose & Galactose & Sialic acid & Amino sugars \\
\hline 1 & Control & 10 & $6.88(0.24)$ & $27.04(1.21)$ & $20.77(1.22)$ & $8.08(0.12)$ & $26.62(2.44)$ \\
& Reserpine & 8 & $6.21(0.36)$ & $31.43(1.57)$ & $21.06(2.01)$ & $8.16(0.22)$ & $28.46(1.98)$ \\
& & & & & & & \\
2 & Control & 15 & $6.66(0.52)$ & $30.04(0.93)$ & $23.43(1.36)$ & $8.72(0.16)$ & $31.09(2.20)$ \\
& Reserpine & 13 & $7.73(0.40)^{3}$ & $24.64(2.01)$ & $28.49(1.25)^{3}$ & $9.92(0.13)^{3}$ & $29.02(2.02)$ \\
& & & & & & \\
3 & Control & 10 & $6.12(0.35)$ & $29.93(1.08)$ & $22.71(0.95)$ & $8.53(0.08)$ & $29.47(1.67)$ \\
& Reserpine & 9 & $6.00(0.44)$ & $29.81(0.87)$ & $23.07(1.11)$ & $8.00(0.17)$ & $30.49(1.76)$ \\
\hline
\end{tabular}

${ }^{1}$ Data expressed as percentage of total carbohydrate \pm S.D.

${ }^{2} \mathrm{~N}$, number of animals.

${ }^{3}$ Significance of $P<0.005$ when compared to parallel control or group 1 or 3 values.

\section{DISCUSSION}

The results of these experiments indicate that the chronic administration of pilocarpine, but not of isoproterenol, to normal rats increases the protein and carbohydrate contents of pulmonary secretions collected by whole lung lavage. The lack of effect of isoproterenol, which was previously found to cause submucosal gland hypertrophy and to increase goblet cell numbers in the rat airways (16), seems to be related to the fact that this agent primarily appears to affect glycoprotein synthesis rather than discharge $(13,16)$. By contrast, chronic pilocarpine administration was found to cause its effect indirectly on discharge, with associated gland hypertrophy $(13,16)$. Pulmonary secretions are known to be under autonomic control, and both parasympathomimetic drugs like pilocarpine and sympathomimetic drugs increase glycoprotein secretion in several species (21). The effect of the latter type of drug seems to be mediated through $\beta$-receptors (21).
Our results also indicate that previous treatment with reserpine enhances the effects of chronic isoproterenol and pilocarpine administration on the protein and carbohydrate content of pulmonary lavage fluid in the rat. Thus, the effect of pilocarpine was significantly greater than that observed in control rats, and isoproterenol, which failed to increase the lavage fluid glycoprotein content in control animals, caused an increase in the glycoprotein content of the lavage samples from reserpine-treated rats, which was comparable to that induced by pilocarpine in control samples. These observations suggest that previous treatment with reserpine enhances secretory activity in the rat airways. The finding of an increased release of glycoprotein confirms previous observations (10) and suggests that pretreatment with reserpine modifies cellular metabolism or glycoprotein turnover rates in the rat airways. This view is supported by the observation that there were changes in the carbohydrate components of the secreted glycoproteins in the lavage fluid of reserpine-treated rats receiving pilocarpine in 
a chronic fashion. This did not occur in similarly treated control rats.

Pretreatment with reserpine also enhanced the effects of chronic isoproterenol and pilocarpine administration on lavage lipid content. There are, however, differences in the effect of the two secretagogues on lung lavage lipids. Thus, isoproterenol appears to cause an increase in total lipids with no change in the percentage of distribution of neutral lipids, cholesterol, and phospholipids. By contrast, pilocarpine causes an increase in the phospholipid fraction and a decrease in the other two, an effect which was not observed in lavage samples from control rats. These findings suggest that pretreatment with reserpine also alters lipid metabolism in the lung, a view also supported by previous studies on unstimulated lavage samples from reserpine-treated rats (10). The effect of reserpine pretreatment on pulmonary lavage phospholipids is likely to involve alterations in the secretory activity of alveolar type II pneumocytes, which are known to be the source of phospholipid in pulmonary fluids (19).

The present results also indicate that the effects of reserpine on the glycoproteins and lipids of pulmonary lavage fluid are no longer apparent 13 days after cessation of the daily injections of this drug. This suggests that the metabolic changes caused by reserpine on the rat airways are reversible. It is not possible on the basis of the present and previous findings (10) to clearly define the mechanism through which pretreatment with reserpine increased the discharge of glycoproteins and lipids in the rat pulmonary fluids, but it is clear that this mechanism involves an enhanced sensitivity to autonomic agents and, furthermore, that it is not related to an irreversible metabolic lesion.

Hypersecretion of mucus glycoproteins is a prominent feature of several pulmonary diseases, including cystic fibrosis $(2,4,5$, 13), and there may be alterations in the composition and physicohemical behavior of pulmonary mucous glycoproteins in CF (2, 5). The reasons for the hypersecretion of respiratory mucus in CF are not entirely clear, but may involve an increased susceptibility to both humoral and luminal influences, particularly to bacterial infection and irritation, from cells already sensitized by the genetic defect. Pretreatment of rats with reserpine appears to sensitize the pulmonary cells in a similar manner and cause an increased secretion of protein and carbohydrate in the airways. Inasmuch as changes similar to those seen in CF have been also found in other exocrine glands of the reserpine-treated rat $(8,9,11,17)$, all of these observations suggest that reserpine administration may result in a molecular lesion in several exocrine tissues which resembles that caused by the genetic defect in CF patients. The proposed animal model should be useful, therefore, in the elucidation of the metabolic lesion in the rat exocrine glands and of its relevance for $\mathrm{CF}$.

\section{CONCLUSION}

Prior treatment with reserpine enhances the effects of the chronic administration of pilocarpine and of isoproterenol on the protein and carbohydrate content of rat pulmonary fluids. This effect seems to involve a sensitization of the secretory elements to the pharmacological effect of the secretagogues and an alteration in glycoprotein turnover, most likely in discharge. Pretreatment of reserpine also alters lipid metabolism in the rat lung and enhances lipid secretion, primarily involving phospholipids. The hypersecretion of organic material induced by reserpine pretreatment in the rat airways resembles that observed in CF. The proposed model can be used to further study the pathogenesis of mucus hypersecretion in this disease.

\section{REFERENCES AND NOTES}

1. Boas, N. F.: Method for the determination of hexosamines in tissues. J. Biol. Chem., 204: 533 (1953).

2. DiSant'Agnese, P. A., and Talamo, R. C.: Pathogenesis and physiopathology of cystic fibrosis of the pancreas. N. Engl. J. Med., 277: 1287, 1341, 1399 (1967).

3. Huang, T. C., Chen, C. T., and Weffler, V.: A stable reagent for the LiebermannBurchard reaction. Application to rapid serum cholesterol determination. Anal. Chem., 33: 1405 (1961).

4. Jones, R., and Reid, L.: Secretory cells and their glycoproteins in health and disease. Br. Med. Bull., 34: 9 (1978).

5. Lopez-Vidriero, M. T., and Reid, L.: Bronchial mucus in health and disease. Br. Med. Bull., 34: 63 (1978).

6. Lowry, O. H., Rosebrough, N. J., Farr, A. L., and Randall, R. J.: Protein measurement with the Folin phenol reagent. J. Biol. Chem., 193: 265 (1951).

7. Lowry, R. R., and Tinsley, I. J.: A simple, sensitive method for lipid phosphorus. Lipids, 9: 491 (1974)

8. Martinez, J. R., Adelstein, E., Quissell, D. O., and Barbero, G. J.: The chronically reserpinized rat as a possible model for cystic fibrosis. I. Submaxillary gland morphology and ultrastructure. Pediatr. Res., 9: 463 (1975).

9. Martinez, J. R., Adshead, P. C., Quissell, D. O., and Barbero, G. J.: The chronically reserpinized rat as a possible model for cystic fibrosis. II. Composition and cilioinhibitory effects of submaxillary saliva. Pediatr. Res., 9: 470 (1975).

10. Mawhinney, T. P., Feather, M. S., Martinez, J. R., and Barbero, G. J.: The chronically reserpinized rat as an animal model for cystic fibrosis: acute effect of isoproterenol and pilocarpine upon pulmonary lavage fluid. Pediatr. Res. 13: 760 (1979)

11. Perlmutter, J., and Martinez, J. R.: The chronically reserpinized rat as a possible model for cystic fibrosis. VII. Alterations in the secretory response to choloecystokinin and to secretin from the pancreas in vivo. Pediatr. Res., 12: 188 (1978).

12. Poorthuis, J. H. M., Yazaki, P. J., and Hostetler, K. Y.: An improved two dimensional thin-layer chromatography system for the separation of phosphatidyl glycerol and its derivatives. J. Lipid Res., 17: 433 (1976).

13. Reid, L.: Animal models in clinical disease. Ciba Found. Symp. 54: 297 (1978),

14. Rouser, G., Kritchevsky, G., and Yamamoto, A.: Column chromatographic and associated procedures for separation and determination of phosphatides and glycolipids. In: G. G. Marinette: Lipid Chromatographic Analysis. Vol. 1, p. 272 (Marcel Dekker, Inc., New York, 1967).

15. Sturgess, J., and Reid, L.: An organ culture study of the effect of drugs on the secretory activity of human bronchial submucosal glands. Clin. Sci. (Ont.), 43: 533 (1972).

16. Sturges, J., and Reid, L.: The effect of isoprenaline and pilocarpine on (a) bronchial mucus secreting tissue and (b) pancreas, salivary glands, heart. thymus, liver and spleen. Br. J. Exp. Pathol., 54: 388 (1973).

17. Thompson, F. E., Quissell, D. O., Williams, C. H., and Martinez, J. R.: The chronically reserpinized rat as a possible model for cystic fibrosis. IV. The protein composition of pulmonary lavage fluid. Pediatr. Res., 10: 632 (1976).

18. Tuckley, B., and Storry, J. R.: An improved method for thin layer chromatography of plasma lipids by single development. Lipids, 9: 493 (1974).

19. VanGolde, L. M. G.: Metabolism of phospholipid in the lung. Am. Rev. Respir. Dis., 114: 997 (1976).

20. Warren, L.: The thiobarbituric acid assay of sialic acids. J. Biol. Chem., 234: 1971 (1959).

21. Widdicombe, J. G.: Control of secretion of tracheobronchial mucus. Br. Med. Bull., 34: 57 (1978)

22. Requests for reprints should be addressed to: Dr. T. P. Mawhinney, Department of Biochemistry, University of Missouri School of Medicine, Columbia, MO 65210 (USA).

23. Received for publication April 9, 1979

24. Accepted for publication September 26, 1979. 